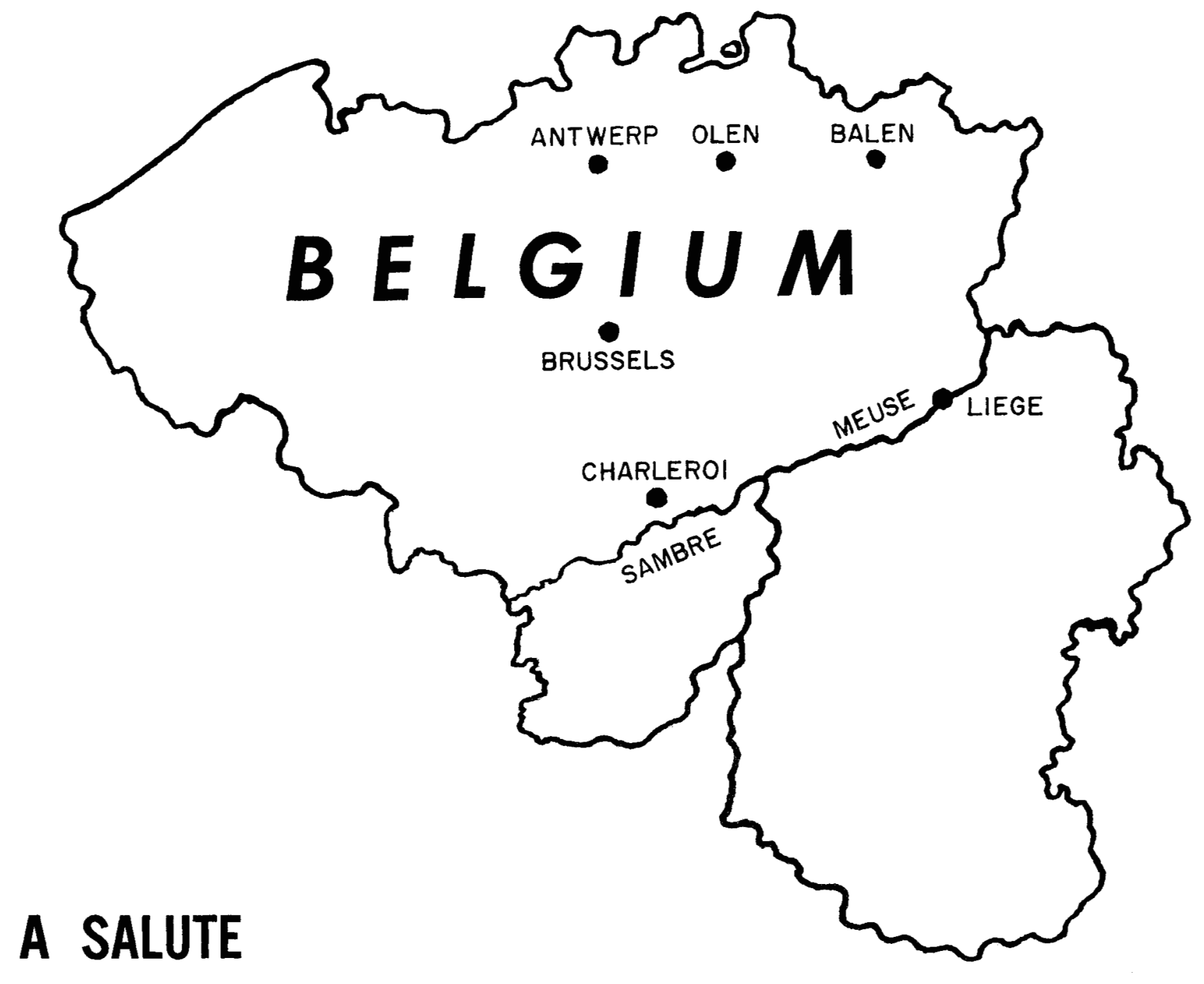

\title{
TO THE METALLURGISTS OF BELGIUM
}

A small country with only 9 million people, hence a relatively small internal market, with its present-day ferrous and nonferrous mineral deposits almost nonexistent, Belgium's long metalworking tradition has, nevertheless, carved a prominent place for,

\section{Metallurgy in Belgium}

The ferrous metals industry ranks eighth in world production and, together with its economic partner, Luxembourg, is the world's largest steel exporter. Belgium is also moving ahead on the technological front, and its National Metallurgical Research Center-CNRM-has perfected techniques for the production of high-quality basic-bessemer steel which is the backbone of its ferrous production.

The nonferrous metals industry is probably the most important in Europe and, on a world-wide basis ranks first in cobalt, second in zinc, and third in copper. Its perfection of methods of radium production is history, as is its more recent production of uranium. Today, in the technological forefront are commercial techniques for the production of such metals as germanium and high-purity silicon.

The Belgian metallurgist can look with pride on his accomplishments. 